\title{
The Importance of the Glissonean Approach and Laennec Capsule Concept in Open Anatomical Liver Resections: What we Need to Know
}

\author{
Aleksandar Karamarković, ${ }^{1,2}$, Jovan Juloski², Vladica Ćuk², Uroš Janković \\ 'Faculty of Medicine University of Belgrade, Serbia \\ ${ }^{2}$ Clinic for Surgery “Nikola Spasić", University Clinical Center "Zvezdara”, Belgrade, Serbia
}

\section{ABSTRACT}

The Glissonean pedicle approach in liver surgery provides new knowledge of the surgical anatomy of the liver and advances the technique of liver surgery. Extrafascial dissection of Glissonean pedicle without opening the liver substance, proposed by Takasaki, represents an effective and safe technique of anatomic liver resection. Presented approach allows early and easy ischemic delineation of appropriate anatomic liver territory (hemiliver, section or segment) to be removed with selective inflow vascular control. It is not time consuming and it is very useful in re-resection, as well as oncological reasonable. According to the Sugioka's proposal, for technical standardization, it is important to recognize the four anatomical landmarks; the Arantius plate, the umbilical plate, the cystic plate and the Glissonean pedicle of the caudate process $(\mathrm{G} 1 \mathrm{c})$, and six Gates defined by the four anatomical landmarks. For the right extrahepatic Glissonean pedicle isolation, the cystic plate cholecystectomy should be the first procedure, whereas for the left, Arantius plate or the umbilical plate should be detached from Laennec's capsule at first. Pedicles can be isolated by connecting Gates each other. Further peripheral pedicles could be pulled out to the hepatic hilum and transected safely. In conclusion, the extrahepatic Glissonean pedicle approach based on Laennec's capsule would standardize anatomical liver resection including laparoscopic and robotic liver resection.

Key words: anatomical liver resection, Glissonean approach, Laennec's capsule, extrafascial dissection

\section{INTRODUCTION}

Widening the range of indications and the occurrence of changes and technical improvements in order to minimize postoperative mortality and morbidity, led to an impressive growth of hepatic resections (1). Hepatic failure and hemorrhage risk both, still make hepatectomies very challenging procedures, although the contemporary criteria for hepatic neoplasm resectabilty are expanded (2-6). Dramatical changes of surgical techniques in hepatic resections have marked the past decades (2-10). Liver parenchyma preservation, as much as possible, with minimum blood loss, remain the hallmarks of liver surgery improvements (1-10).

\author{
Corresponding author: \\ Professor Aleksandar Karamarković, \\ $\mathrm{MD}, \mathrm{PhD}$, FACS \\ Faculty of Medicine University of \\ Belgrade \\ Clinic for Surgery "Nikola Spasić" \\ University Clinical Center "Zvezdara" \\ Belgrade, Serbia \\ Dimitrija Tucovica Str. 161, Belgrade \\ 11000, Serbia \\ E-mail: alekara@sbb.rs
}

Received: 16.03.2020

Accepted: 20.04.2020 
Isolating Glissonean pedicle in anatomical hepatic resections is considered crucial in terms of safety and oncological curability, and aiming to do so without breaching the hepatic parenchyma is considered quintessential. Even today, adequate understanding of anatomy represents the main problem in standardizing this approach (11).

\section{Glissonean pedicle isolation - history}

In 1949., Ichio Honjo (Kyoto University) and later on in 1952., J. L. Lortat-Jacob (Paris University) were the first who performed the anatomical right hepatectomy, using the so-called "classic" (intrafascial-extrahepatic) hilar dissection (HD) of the hepatic artery, portal vein and bile duct in the hepatoduodenal ligament for the controlled hepatectomy $(7,8,10)$. Extensive scarring due to previous surgery, risk of lesions of anomalous biliary ducts and vessels are all potential disadvantages or this approach (12-15). Glisson and Couinaud noticed that elements of portal triad are enveloped within a thick connective tissue and are surrounded by a fibrous sheath (Glissonean pedicle). This was the foundation for the initial proposal by Couinaud in 1957, that suprahilar vascular control of Glissonean pedicle could serve as an important alternative to classical HD for controlling vascular inflow to the liver. This technique includes the extrafascial dissection of the whole sheath of the pedicle and its control and division "en-bloc" (16). Actually, the Glissonean tree, inside the liver substance represent an important structure of internal anatomy and architecture of the liver. Three approaches to the portal pedicles are described by Couinaud (17). Couinaud, Ton That Thung, Lin and Quang utilize anatomical fissures as point of entries to the liver in so called anterior transfissural (extrafascial) approach. By splitting the liver parenchyma down along the appropriate fissure, the pedicle of interest could be approached $(16,18)$ (video 1).

The extrahepatic - extrafascial dissection of left Glissonean pedicle at the hepatic hilum without liver transection, for the left hepatectomy, was previously reported by Couinaud in 1985. and later by Lazorthes in $1993(19,20)$. Ken Takasaki in 1986. described the surgical technique so called "Glissonean pedicle transection method" $(21,22)$. Technique is based on detachment of the hilar plate from above the basis of segment $4 \mathrm{~b}$ and extrafascial-extrahepatic dissection of the main (primary) left and right, as well as both right anterior and posterior sectional (secondary) pedicles, without opening the liver parenchyma $(21,22)$ (video 2). Opposite to anterior transfissural approach, Galperin in
1989. described a digital "hooking" technique for the isolation of portal pedicles through an extrafascialintrahepatic posterior approach after making a " $\mathrm{T}$ " shaped incision on the proper sites on posterior surface of the liver, and division of a substantial amount of the hepatic tissue (23). "Posterior intrahepatic approach" to the appropriate Glissonean pedicle, through through the dorsal fissure of the liver, after making a proper perihilar hepatotomies, was proposed in 1992 by Launois and Jamieson (24). In order to prevent some possible injuries of short hepatic veins or branches of MHV, Machado made modifications that included making small incisions around the hilar plate and strictly instrumental isolation of the pedicle (25-27). Laennec's hypothesis about a separate liver membrane, whose existence on the liver surface, was not only confirmed, but it was also proved that it covers the Glissonean pedicles and major hepatic veins all the way into the parenchyma of the liver (11). Therefore, isolation of Glissonean pedicles can be done without parenchymal damage, using the thin space between the pedicle and Laennec's capsule (11).

\section{Surgical anatomy of the liver - history}

Waleus's description of a sheet containing the portal vein, hepatic artery and the bile duct was the first to be published in 1640 (28), and two years later Glisson reported about the pedicle in the liver (29). First years of the 19th century brought us a significant discovery of a separate membrane (Laennec's membrane/capsule), which is different from a serosal sheet of the liver (30). The plate system, a fibrous thickening of the Glissonean sheath, was introduced by Couinaud (31). He also proved that Laennec's capsule is not continuous with the pedicle (17). It is an interesting fact that Couinaud observed and published, in great detail, various pathological findings on Laennec's capsule; but somehow ignored its importance, which led to neglection of Laennec's capsule for the next two centuries $(11,17)$. A histologic study from 2008, on cadaveric livers, clearly proved the existance of Laennec's capsule as a separate entity (32). Most recent findings published by Sugioka described Laennec's capsule as a separate membrane, a dense fibrous layer beneath the serosal lining, enveloping also the bare area, cystic fossa and Glissonean pedicles and major hepatic veins (11). Sugioka reported that the Glisson's sheath and Laennec's capsule can be divided outside and inside the liver. Glissonean pedicles can be separated from Laennec's capsule and not only the main portal pedicles but also the sectional and segmental pedicles 
can be approached suprahilar without liver dissection. This concept supports Takasaki's procedure (33).

\section{The Glisson's sheath and the plate system of the liver}

Couinaud referred to the vasculo-biliary sheath as the most important structure of the liver in his book entitled Surgical Anatomy of the Liver Revisited (17). The Glisson's sheath wraps the portal vein, hepatic artery and bile duct and these three structures are therefore regarded as forming one morphological system, which since then has been referred to as the Glissonean system $(34,35)$. The hepatic vein system is another system inside the liver. Major hepatic veins runs along the liver fissures, between the anatomical sections, and thus represents a very important internal anatomical landmarks.

The Glisson's sheath, by fibrous condensation, forms a thick plate at the inferior part of the liver, which represents the plate system. The central part of this system, is the hilar plate which extends on the right into the cystic plate, and on the left side into the umbilical plate and Arantius plate (figure 1). The hilar plate, as well as the whole plate system can be detached from the above the base of the segment $4 \mathrm{~b}$, cystic fossa and umbilical fissure (figure 2), because there are no branches originates from the anterior margin or the upper surface of the hilar plate (17). When the hilar plate or plate system are pulled down after detachment from Laennec's capsule of the liver, the primary and secondary right or left Glissonean pedicles can be easily approached outside the liver (35) (figure 3 ). The most important is the fact that any variation, particularly in the arteries and bile ducts, occurs under the hilar plate. Therefore, suprahilar dissection and control of the Glissonean pedicle is safe. From the surgical point of view, it is very important to keep intact the plate system, especially Arantius plate and we do not have to consider about any anatomical variation above the hilar plate $(17,35)$.

\section{Surgical anatomy of the liver - based on Laennec's capsule concept proposed by Sugioka}

Traditional description of hepatic anatomy says about serosal covering of the whole liver, except at the naked area and at cystic fossa, Glissonean pedicle's that are adjacent to intrahepatic parenchyma and the hilar plate covering only the outer circumference of the Glissonean pedicles (11). However, contemporary

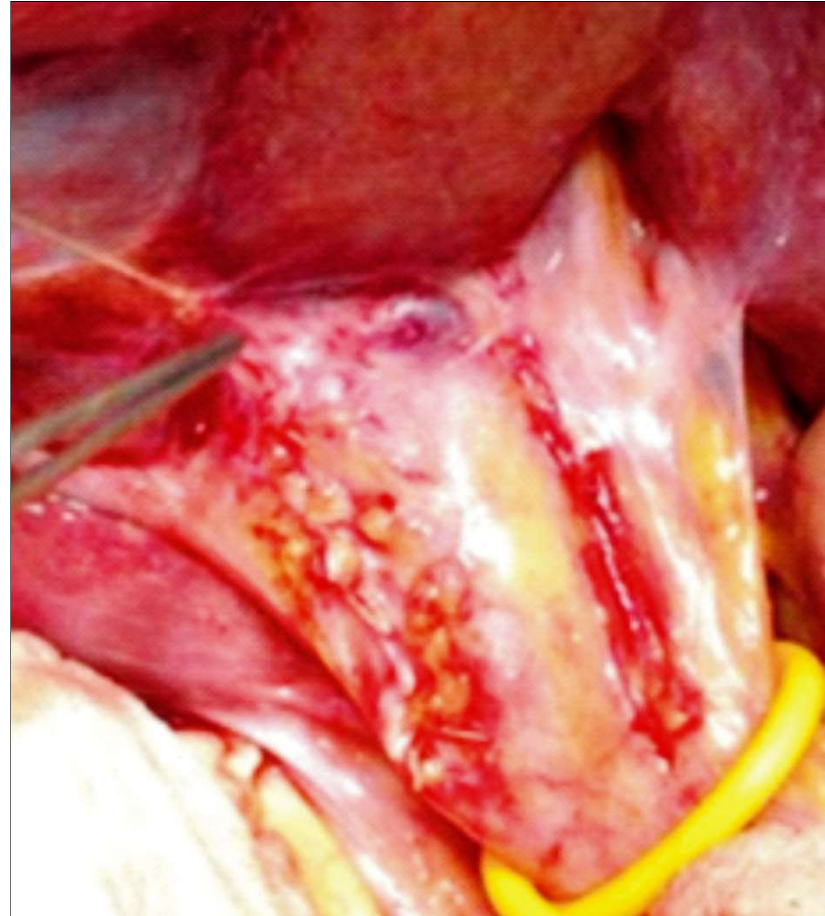

Figure 1 - The Plate system of the liver

anatomical knowledge of the liver is based on Laennec's capsule, and it represents it as a proper hepatic lining which covers the whole subserosal part of the liver, naked area and intrahepatic parenchyma surrounding the Glissonean pedicles' surface and major hepatic veins (11). This is also proven histologically as a thin fibrous layer on the naked area (36). A similar layer

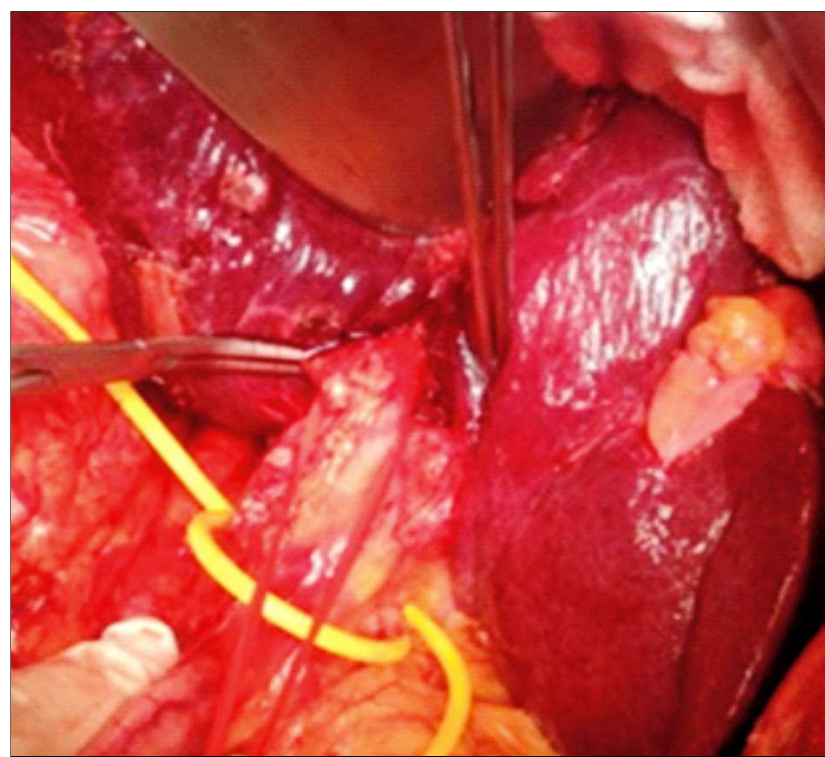

Figure 2 - Takasaki's technique of extrahepatic-extrafascial isolation and clamping of the right main Glissonean pedicle (RMP) after detachment of the hilar plate from above the base of segment S4b 


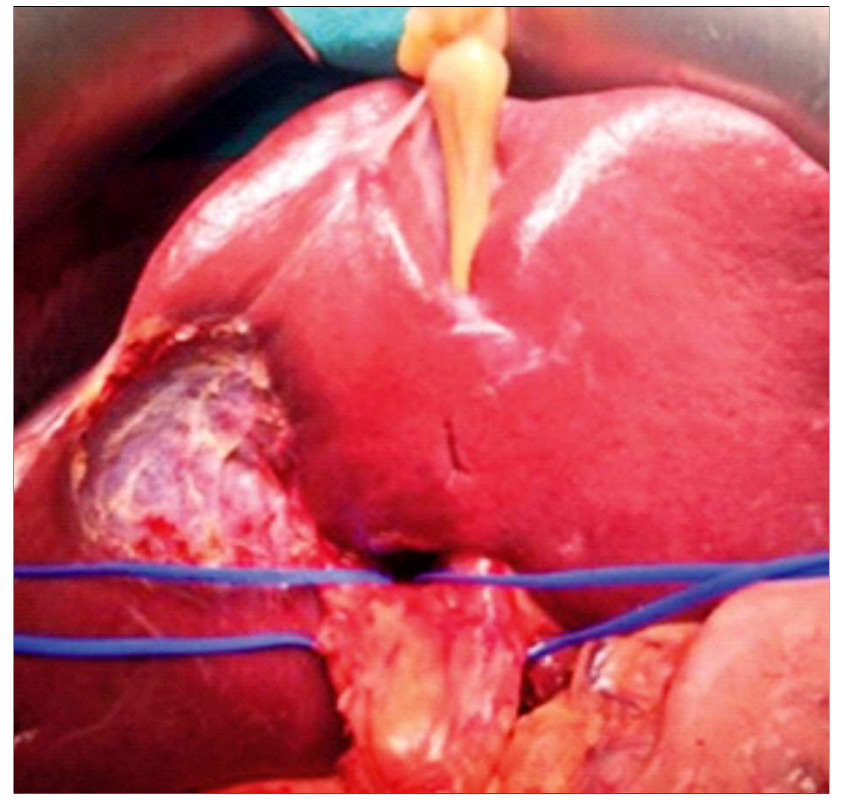

Figure 3 - Takasaki's technique: extrahepatic control of the right and left main Glissonean pedicles

observed on the outside of the Glissonean pedicles, as a lining of the hepatic veins and the IVC wall. Laennec's capsule was also observed close to the adrenal gland with confirmed natural gaps between Laennec's capsule and the adjacent tissues at different sites, such as Glissonean pedicles, hepatic veins, and the IVC (36).

At the level of the hepato-caval confluence, the Laennec's capsule structure is composed of two layers surrounding the major hepatic veins: one is derived from the proper membrane (hepatic Laennec's capsule) and the other from the pericardium (cardiac Laennec's capsule) (37). A space between the pedicle (the plate system) and Laennec's capsule, at the level of hepatic hilum, enables suprahilar, extrahepatic dissection without parenchymal injury. The plate system, a fibrous thickening which contains vaginal ductuli (32), represents a helpful landmark for extrahepatic Glissonean pedicle isolation. Sugioka et al., also proposed the Inter-Laennec approach as a new strategy for exposure of the hepatic vein by entering the space between the two layers of Laennec's capsule: one derived from the proper membrane (hepatic Laennec's capsule) and the other from the pericardium (cardiac Laennec's capsule). Cranio-caudal parenchymal dissection is required to maintain the inter-Laennec space. Transection of the IVC-ligament is helpful for entry into the inter-Laennec space around the confluence of the RHV $(37,38)$. Hence, Sugioka's novel concept clarifies the surgical technique for systematic extrahepatic Glissonean pedicle isolation (11).
Standardization of the systematic extrahepatic Glissonean pedicle isolation based on

Laennec's capsule - Sugioka's approach

As noted earlier, it is of outmost importance to determine the Arantius plate, the umbilical plate, the cystic plate, and the caudate process pedicle (G1c) (anatomical landmarks) and "six gates" which represent gaps between Laennec's capsule and the Glissonean pedicles as part of the plate system. These gaps could be entered without parenchymal injury and the extrahepatic Glissonean pedicle isolation could be standardized (11).

\section{Extrahepatic approach to the Glissonean pedicles of the right hemiliver}

Using following technique, „primary“ right main Glissonean pedicle, as well as "secondary branches" right anterior and posterior sectional Glissonean pedicles, could be dissected and isolated extrahepatically, without opening the liver tissue (figure 4). Sugioka proposed "the cystic plate cholecystectomy" as the first step procedure, detaching the cystic plate from above the Laennec's capsule covering the cystic fossa (video 3); this maneuver leads to the precise exposure of the right anterior Glissonean pedicle and at the same time, Gates IV and V could be identified (11). By connecting the Gates IV and V as shown in, the extrahepatic anterior Glissonean pedicle could be isolated. Further dissection of Gate V and VI, allows extrahepatic control of posterior Glissonean pedicle

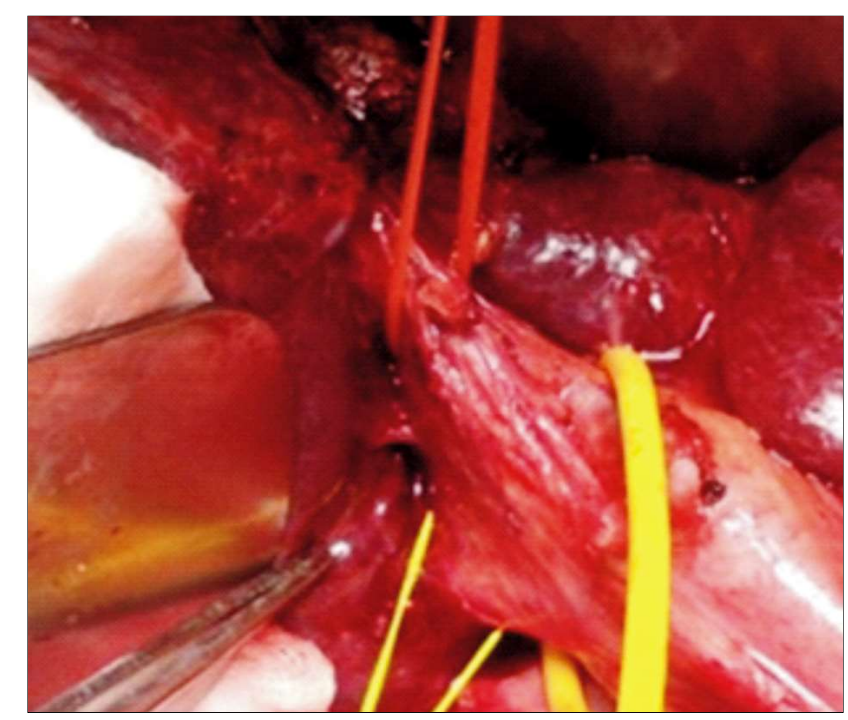

Figure 4. Isolation of the right primary and secondary Anterior and Posterior Glissonean pedicles outside the liver according to the Sugioka's systematic approach using the Gates IV-V and VI-VII 
(figure 5). The G1c pedicle could be consistently identified at the entry of the Rouviere's sulcus $(11,35,39)$.

\section{Extrahepatic approach to the Glissonean pedicles of the left hemiliver}

The left pedicle can be approached at the left end of the hilar plate (Gate III), followed by detachment of the Arantius plate from Laennec's capsule in order to identify Gate I. (video 4). By connecting the Gates I and III, left main Glissonean pedicle could be taped and pulled down for the clamping or transsection. The Arantius ligament should be left intact, since the tertiary branch of the left caudate lobe (G1l) and possible anomalous right posterior sectional bile duct connecting to the left hepatic duct, are at the dorsal side of the Arantius plate. Therefore, surgeons do not have to consider any anatomical variations of the left pedicle, when using this suprahilar approach (39). Detachment of the umbilical plate from Laennec's capsule covering the umbilical fossa allow opening the Gate II. By connecting the Gates I,II and III, the Glissonean pedicles of segments 2 and 3 (G2 and G3) could be isolated separately or "en-bloc". Afterwards each extrahepatic Glissonean pedicle could be isolated precisely in the same manner; Glissonean pedicles for segment 4 (G4) or the umbilical portion (G2 + G3 + G4) of the left main pedicle $(11,35,39)$.

\section{Approach to the tertiary branches}

According to Takasaki's concept of liver anatomy, one secondary Glissonean pedicle has six to eight tertiary Glissonean pedicles $(35,39)$. The territory of a single tertiary pedicle does not correspond to Couinaud's segment. Takasaki therefore refers to the area fed by one tertiary branch as a cone unit of the liver $(21,22,40)$. Couinaud's segments consist of three or four cone units. The tertiary branches on the left liver can easily be approached because they can be seen along the umbilical portion and marked with anatomical landmark of the root of the round ligament and recessus of $\operatorname{Rex}(21,35)$.

However, on the right liver, the tertiary pedicles cannot be displayed or seen on the liver surface or at region of the hepatic hilum. Extrahepatic clamping of the previously isolated secondary Glissonean pedicles, allow ischemic demarcation of the right anterior or right posterior anatomical section of the liver, confirming the borderline (right fissure of the liver) between the anterior and posterior sections. Some of the tertiary branches from near the hepatic hilus can be

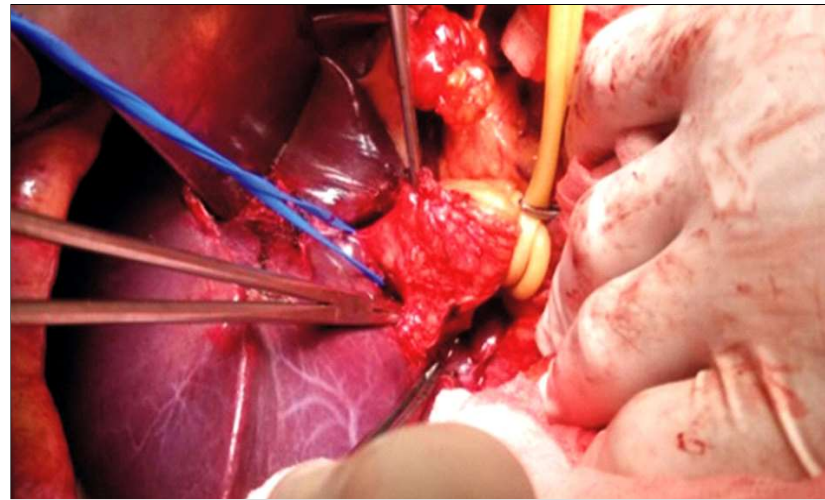

Figure 5 - Dissection of the Gates V and VI, allows the extrahepatic control of the posterior Glissonean pedicle (Sugioka's concept of systematic approach)

approached around the secondary pedicles, by pulling down and extrahepaic exteriorisation. The tertiary branches, which originate from deep portions of the secondary branches, should be approached and isolated intrahepatically (figure 6), after transsection of the appropriate liver parenchyma along transfissural plane (borderline) between Takasaki's segments. Further, clamping of the isolated tertiary Glissonean pedicle, delineate the anatomic segment orientated territory of the liver to be removed (anatomical subsegmentectomy or segmentectomy) $(35,39)$.

\section{Advantages and limitations}

Reduction of intraoperative hemorrhage, risk of contralateral vasculature and biliary drainage, portal triad closure time and expedition of hepatic transection are all major advantages of the Glissonean approach in

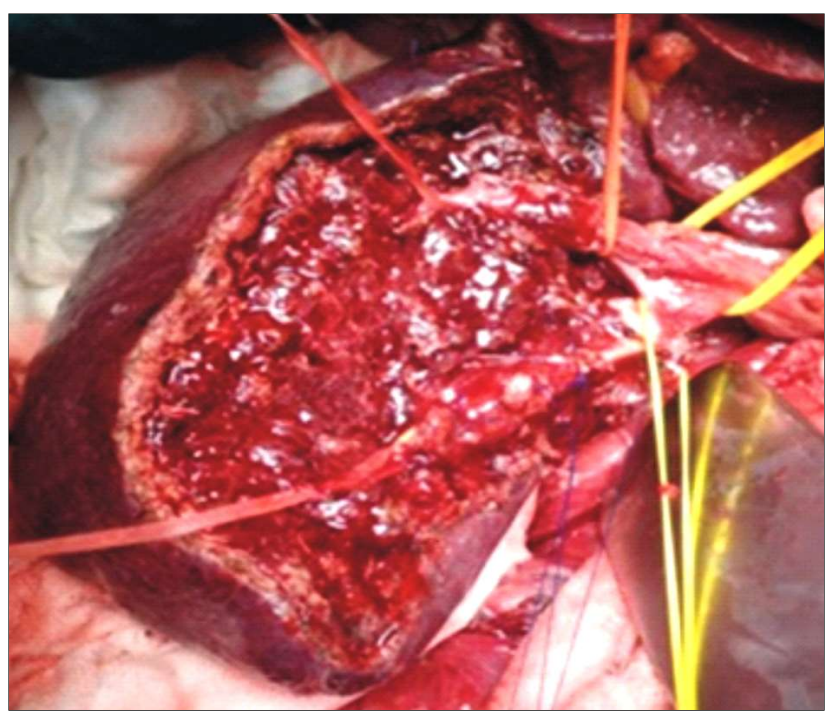

Figure 6 - Right sided intrahepatic anatomy of the Glissonean tree after removal of segments S5 and S6 
liver surgery $(41,42)$. Introduction of vascular staplers in liver surgery also contributed to higher security (8,43-46).

Complex procedures such as hepatic resections, mandate precise knowledge of liver anatomy, flawless surgical technique and adequate volume of the remnant liver (1-4,6-8,47). High mortality rate of 20 per cent for major liver resections in the late 1970s was major motivation for surgeons to make a lot of effort in achieving intraoperative control of blood loss and reduction of intraoperative bleeding $(47,48)$.

The extrafascial dissection of the whole Glissonean pedicle is highly important technique that can be very useful in specific circumstances in hepatic surgery, like repeated abdominal operations, cirrhotic liver surgery or patients with anomalous vascular and biliary variations. Terminology of addressing this technique is still present (Glissonean approach, extra-Glissonean approach, Glissonean pedicle transection method, posterior intrahepatic approach, suprahilar Vascular control, perihilar posterior approach, superficialisation of Glissonean pedicles) $(21,49)$. Regardless if the variety of names and titles, the main surgical concept is the same, and is based on Couinaud's anatomical facts and observations that portal triad elements inside the liver substance, are enveloped with fibrous Glissonean sheath, thus representing an important structure of internal architecture of the liver $(16,19)$. The extrafascial-Glissonean pedicle approach in hepatic surgery grants new knowledge of the surgical anatomy of the liver and upgrades the technique of liver surgery (35). Contrary to "classic" intrafascial dissection, this technique encompasses extrafascial isolation of the whole sheath of Glissonean pedicle and its division "en-bloc". Glissonean pedicles can be approached intrahepatically or extrahepatically. Appropriate pedicle and hepatic vein can be transected safely and expeditiously by using vascular staplers in this situation (50). The second advantage of this technique can be experienced in swift and straightforward definition of the anatomic territory of the liver to be removed. Selective clamping of the appropriate isolated pedicle exposes further ischemic demarcation of anatomical part of the liver of interest (hemiliver, section or even segment) as well as delineation of resectional planes (23-27).

Recent advances of presented surgical technique includes liver hanging maneuver and some modifications with two tapes to control the main fissure of the liver or various liver resections using hanging maneuver by three Glisson's pedicles and three hepatic veins $(51,52)$. Figueras and his team showed, in the first prospective randomized study which compared extrafascial Glissonean approach versus traditional hilar dissection in major liver resections, that "en block" stapling pedicle transection was secure and quicker than traditional hilar dissection (7). Comparable results for safety and operative duration were published in other studies $(39,53-56)$. Intrafascial hilar dissection is difficult, on occasion hazardous and more time consuming when compared to extrafascial isolation of Glissonean pedicle. Risk of potentially injuring the contra-lateral vasculature and bile ducts is significantly reduced with dissection above hepatic hilum (57). Intrahepatic dissection is safe as extrahepatic hilar division as far as intraoperative blood requirements and morbidity are concerned, one study showed; but biliary complications are more severe in patients undergoing extrahepatic division of the portal pedicle (54). Anatomic segment-oriented resections show numerous advantages assets including prevention of postoperative liver failure especially in elderly or patients with underlying liver disease, reduction of blood loss as well as lower postoperative mortality and morbidity rates. Should a segmental or major resection be performed, in terms of technical feasibility of both procedures, is still an unresolved dilemma. Sectionectomies and segment-oriented resections are very facilitated with the suprahilar extrahepatic control of the Glissonean pedicle. Couinaud and, more recently, Takasaki have noted that Laennec's capsule (formerly called "the Glissonean capsule") continues covering the liver parenchyma up to the segmental divisions $(21,22,24,58)$.

While generally associated with low perioperative morbidity and mortality (less than 1\%), the use of the Glissonean approach can be technically challenging in some cases $(59,60)$. When performing the suprahilar control of Glissonean pedicle, gentle handling of anatomic structures is extremely important (61). Difficulty in encircling the pedicles or parenchymal bleeding during liver dissection at the suprahilar area are the most common causes of technical failure (60). Also, the Glissonean approach may not be the best approach for tumors closely adjacent to the hilum, since transection of Glisson's pedicles can result in intraoperative tumor spread and recurrence (61).

\section{CONCLUSION}

Extrahepatic-extrafascial dissection and isolation of Glissonean pedicle, introduced by Takasaki and further established by Sugioka, represents both compelling and secure surgical technique of anatomical liver resection. This approach allows prompt and easy ischemic 
delineation of appropriate anatomical liver territory to be removed (hemiliver, section, segment) with particular inflow vascular control. Also, it is very time sparing and it is very useful in redo liver surgery. This technique also has oncological advantages: dissemination of neoplastic cells is prevented with early initial ligation of the Glissonean pedicle, while removal of micrometastases at the root of the pedicle with adequate resectional margin is achieved with the anatomical concept of resections itself. It must be stressed that patient selection should be strict. Finally, according to our opinion, surgical technique of anatomical liver resections based on the Laennec's capsule concept, should be a part of knowledge and skills of HPB surgeon.

\section{Conflict of interest}

\section{All author declare that they have no conflict of interest.}

\section{REFERENCES}

1. Dan RG, Cretu OM, Mazilu O, Sima LV, lliescu D, Blidisel A, et al. Postoperative morbidity and mortality after liver resection. Retrospective study on 133 patients. Chirurgia (Bucur). 2012; 107(6):737-41.

2. Chirica M, Scatton O, Massault PP, Aloia T, Randone B, Dousset B, et al. Treatment of stage IVA hepatocellular carcinoma: should we reappraise the role of surgery? Arch Surg. 2008;143(6):538-43; discussion 43

3. Pawlik TM, Schulick RD, Choti MA. Expanding criteria for resectability of colorectal liver metastases. Oncologist. 2008 13(1):51-64.

4. Gonzalez HD, Figueras J. Practical questions in liver metastases of colorectal cancer: general principles of treatment. HPB (Oxford). 2007;9(4):251-8.

5. Minagawa M, Yamamoto J, Miwa S, Sakamoto Y, Kokudo N, Kosuge $\mathrm{T}$, et al. Selection criteria for simultaneous resection in patients with synchronous liver metastasis. Arch Surg. 2006 141(10):1006-12; discussion 13.

6. Nuzzo G, Giuliante F, Ardito F, Vellone M, Pozzo C, Cassano A, et al. Liver resection for primarily unresectable colorectal metastases downsized by chemotherapy. J Gastrointest Surg. 2007; 11(3):318-24.

7. Figueras J, Lopez-Ben S, Llado L, Rafecas A, Torras J, Ramos E, et al. Hilar dissection versus the "glissonean" approach and stapling of the pedicle for major hepatectomies: a prospective, randomized trial. Ann Surg. 2003;238(1):111-9.

8. Aragon RJ, Solomon NL. Techniques of hepatic resection. $J$ Gastrointest Oncol. 2012;3(1):28-40.

9. Karamarković A, Doklestić K, Popović N, Gregorić P, Vujadinović ST, Milić N. Suprahilar vascular control and stapling device transection of Glissonian pedicle in major and minor hepatectomies. HepatoGastroenterol.2013;60(128):2060-8.

10. Lortat-Jacob JL, Robert HG. Hepatectomie droite reglé. Presse Med 1952:60(26):549-51.

11. Sugioka A, Kato Y, Tanahashi Y. Systematic extrahepatic Glissonean pedicle isolation for anatomical liver resection based on Laennec's capsule: proposal of a novel comprehensive surgical anatomy of the liver. J Hepatobiliary Pancreat Sci. 2017;24(1):17-23.
12. Meunier B, Lakeha MI, Tay KH, Y Malledant, B Launois. Surgical complications and treatment during resection for malignancy of the high bile duct. World J Surg. 2001;25(10):1284-8.

13. Lo CM, Fan ST, Liu CL, Lai EC, Wong J. Biliary complications after hepatic resection: risk factors, management, and outcome. Arch Surg. 1998;133(2):156-61

14. Miyagawa S, Makuuchi M, Kawasaki S, Kakazu T. Criteria for safe hepatic resection. Am J Surg. 1995;169(6):589-94.

15. Icoz G, Kilic M, Zeytunlu M, Celebi A, Ersoz G, Killi R, et al. Biliary reconstructions and complications encountered in 50 consecutive right-lobe living donor liver transplantations. Liver Transpl. 2003; 9(6):575-80.

16. Couinaud C. Le foie; études anatomiques et chirurgicales. Paris: Masson; 1957. French

17. Couinaud C. The vasculo-biliary sheath. Surgical anatomy of the liver revisited. Paris (15, rue Spontini, 75116): C. Couinaud; 1989.

18. Tung TT. Les Résections Majeureset Mineures du Fois. Paris: Masson \& Cie; 1957. French

19. Couinaud C. A simplified method for controlled left hepatectomy. Surgery. 1985;97(3):358-61

20. Lazorthes F, Chiotasso P, Chevreau P, Materre JP, Roques J. Hepatectomy with initial suprahilar control of intrahepatic portal pedicles. Surgery. 1993;113(1):103-8.

21. Takasaki K. Glissonean pedicle transection method for hepatic resection: a new concept of liver segmentation. J Hepatobiliary Pancreat Surg. 1998;5(3):286-91.

22. Takasaki K. Glissonean pedicle transection method for hepatic resection. Tokyo: Springer; 2007.

23. Galperin El, Karagiulian SR. A new simplified method of selective exposure of hepatic pedicles for controlled hepatectomies. HPB surgery : a world journal of hepatic, pancreatic and biliary surgery. 1989;1(2):119-30.

24. Launois B, GG Jamieson. The importance of Glisson's capsule and its sheaths in the intrahepatic approach to resection of the liver. Surg Gynecol Obstet. 1992;174(1):7-10.

25. Machado MA, Herman P, Machado MC. A standardized technique for right segmental liver resections. Arch Surg. 2003;138(8):918-20.

26. Machado MA, Herman P, Machado MC. Anatomical resection of left liver segments. Arch Surg. 2004;139(12):1346-9.

27. Machado MA, Herman P, Meirelles Jr. RF, Bacchella T, Machado MC. How I do it: bi-segmentectomy V-VIII as alternative to right hepatectomy: an intrahepatic approach. J Surg Oncol. 2005;90(1):43-5.

28. Walaeus J. Epistolae duae de motu chyli et sanguinis ad Thomam Bartholeum. Leiden Fransciscus Hackius; 1640.

29. Glisson F. Anatomia hepatis. London: O. Pullein; 1654. Latin

30. Laennec RTH. Lettre sur des Tuniques qui enveloppent certains Visceres, et fournissentdes gaines membraneusesa leurs vaisseaux. 1802. French

31. Couinaud C. Les enveloppes vasculo-biliaires du foie ou capsule de Glisson. Leur inter ${ }^{\wedge}$ et dans la chirurgie vesiculaire, les resctions hepatiques et l'abord du hile du foie. Lyon Chir. 1954:49:589-607. French

32. Hayashi S, Murakami G, Ohtsuka A, Itoh M, Nakano T, Fukuzawa Y. Connective tissue configuration in the human liver hilar region with special reference to the liver capsule and vascular sheath. J Hepatobiliary Pancreat Surg. 2008;15(6):640-7.

33. Yamamoto M, Ariizumi S. Glissonean pedicle approach in liver surgery. Ann Gastroenterol Surg. 2018;2(2):124-8.

34. Gans H. On the subdivision of the liver. Introduction to hepatic surgery. Houston: Elsevier; 1955. p. 1-39.

35. Yamamoto M, Katagiri S, Ariizumi S, Kotera Y, Takahashi $Y$. Glissonean pedicle transection method for liver surgery (with video). J Hepatobiliary Pancreat Sci. 2012;19(1):3-8.

36. Hu Y, Shi J, Wang S, Zhang W, Sun X, Sun B, et al. Laennec's approach for laparoscopic anatomic hepatectomy based on Laennec's capsule. BMC Gastroenterol. 2019;19(1):194.

37. Kiguchi G, Sugioka A, Kato Y, Uyama I. Use of the inter-Laennec approach for laparoscopic anatomical right posterior sectionectomy in semi-prone position. Surg Oncol. 2019;29:140-1.

38. Kiguchi G, Sugioka A, Kato $\mathrm{Y}$, Uyama I. Laparoscopic S7 Segmentectomy using the inter-Laennec approach for hepato- 
cellular carcinoma near the right hepatic vein. Surg Oncol. 2019; 31:132-4.

39. M Yamamoto, S Katagiri, S Ariizumi, Y Kotera, Y Takahashi, H Egawa. Tips for anatomical hepatectomy for hepatocellular carcinoma by the Glissonean pedicle approach (with videos). J Hepatobiliary Pancreat Sci. 2014;21(8):E53-6.

40. Takasaki K, Kobayashi S, Tanaka S, Saito A, Yamamoto M, Hanyu F. Highly anatomically systematized hepatic resection with Glissonean sheath code transection at the hepatic hilus. Int Surg. 1990;75(2):73-7.

41. Fong Y, Blumgart LH. Useful stapling techniques in liver surgery. $J$ Am Coll Surg. 1997;185(1):93-100.

42. Ramacciato G, Aurello $P, D^{\prime}$ 'Angelo $F$, Caramitti $A$, Barillari $P$, Fornasari V. Effective vascular endostapler techniques in hepatic resection. Int Surg. 1998;83(4):317-23.

43. Wang WX, Fan ST. Use of the Endo-GIA vascular stapler for hepatic resection. Asian J Surg. 2003;26(4):193-6.

44. DeMatteo RP, Fong Y, Jarnagin WR, Blumgart LH. Recent advances in hepatic resection. Semin Surg Oncol. 2000;19(2):200-7.

45. Schemmer P, Friess H, Hinz U, Mehrabi A, Kraus TW, Z'Graggen K, et al. Stapler hepatectomy is a safe dissection technique: analysis of 300 patients. World J Surg. 2006;30(3):419-30.

46. Bagul A, McMahon G, Alam F, Dennison AR. Safely dealing with the right hepatic vein during a right hepectomy. Ann R Coll Surg Engl. 2010;92(5):442-3.

47. Poon RT, Fan ST, Lo CM, Liu CL, Lam CM, Yuen WK, et al. Improving perioperative outcome expands the role of hepatectomy in management of benign and malignant hepatobiliary diseases: analysis of 1222 consecutive patients from a prospective database. Ann Surg 2004;240(4):698-708; discussion -10.

48. Poon RT. Current techniques of liver transection. HPB (Oxford). 2007;9(3):166-73.

49. Bismuth $H$. Surgical anatomy and anatomical surgery of the liver. World J Surg. 1982;6(1):3-9.

50. Nanashima A, Sumida Y, Oikawa M, Murakami G, Abo T, Hidaka S, et al. Vascular transection using endovascular stapling in hepatic resection. Hepatogastroenterology. 2009;56(90):498-500.
51. Boudjema K, Veilhan LA, Dupont-Bierre E, Lakehal M. Two tapes to control the main fissure of the liver. Ann Chir. 2002;127(2):149-53.

52. Kim SH, Park SJ, Lee SA, Lee WJ, Park JW, Hong EK, et al. Various liver resections using hanging maneuver by three glisson's pedicles and three hepatic veins. Ann Surg. 2007;245(2):201-5.

53. Cresswell AB, Welsh FK, John TG, Rees M. Evaluation of intrahepatic, extra-Glissonian stapling of the right porta hepatis vs. classical extrahepatic dissection during right hepatectomy. HPB (Oxford). 2009;11(6):493-8.

54. Smyrniotis V, Arkadopoulos N, Theodoraki K, Voros D, Vassiliou I, Polydorou A, et al. Association between biliary complications and technique of hilar division (extrahepatic vs. intrahepatic) in major liver resections. World J Surg Oncol. 2006;4:59.

55. Giordano M, Lopez-Ben S, Codina-Barreras A, Pardina B, Falgueras $\mathrm{L}$, Torres-Bahi S, et al. Extra-Glissonian approach in liver resection. HPB (Oxford). 2010;12(2):94-100.

56. Mouly C, Fuks D, Browet F, Mauvais F, Potier A, Yzet T, et al. Feasibility of the Glissonian approach during right hepatectomy. HPB (Oxford). 2013;15(8):638-45.

57. Launois B. General principles of liver surgery. In: B Launois, GG Jamieson, editors. The posterior intrahepatic approach in Liver surgery. New York, USA: Springer; 2013.

58. Takasaki K, Yamamoto M. Surgical anatomy of the liver in the Glissonean pedicle approach: what we need to know. In: Madoff DC, Makuuchi M, Nagino M, Vauthey JN, eds. Venous Embolization of the Liver: Radiologic and Surgical Practice. Springer: 2011. p.23-28.

59. Chen XP, Qiu FZ. A simple technique ligating the corresponding inflow and outflow vessels during anatomical left hepatectomy. Langenbecks Arch Surg. 2008;393(2):227-30; discussion 31-4.

60. Figueroa R, Laurenzi A, Laurent A, Cherqui D. Perihilar Glissonian Approach for Anatomical Parenchymal Sparing Liver Resections: Technical Aspects: The Taping Game. Ann Surg. 2018;267(3): 537-43.

61. Moris D, Rahnemai-Azar AA, Tsilimigras DI, Ntanasis-Stathopoulos I, Marques HP, Spartalis E, et al. Updates and Critical Insights on Glissonian Approach in Liver Surgery. J Gastrointest Surg. 2018;22(1):154-63. 